Egyptian Journal of Aquatic Biology \& Fisheries

Zoology Department, Faculty of Science,

Ain Shams University, Cairo, Egypt.

ISSN $1110-6131$

Vol. 24(3): 299 - 309 (2020)

www.ejabf.journals.ekb.eg

\title{
Parasitological assessment of the purifying performance of the wastewater station by natural lagoon of Azilal, Morocco.
}

\author{
Youssef A. Idrissi ${ }^{1}{ }^{*}$, Dalale Mansouri ${ }^{2}$, Amina El Yemli ${ }^{3}$,Imane Kherrati ${ }^{1}$, Nabyl Berrid ${ }^{1}$, \\ El Hassan Ghachoui ${ }^{4}$, Ali k. Hussein ${ }^{5}$, Khadija El Kharrim ${ }^{1}$ and Driss Belghyti ${ }^{1}$ \\ 1- Laboratory of Agro-Physiology, Biotechnology, Environment and Quality. Water, Wastewater and \\ Health Team. Faculty of Sciences, Ibn Tofail University, Kénitra, Morocco. \\ 2- Health and Environment Nutrition Laboratory, Faculty of Sciences, Ibn Tofail University, \\ Kenitra, Morocco. \\ 3- Laboratory Environmental Development and Management, Faculty of Letters and Human \\ Sciences, Ibn Tofail University, Kenitra, Morocco. \\ 4- Electrochemical Materials and Environment Laboratory, Faculty of Sciences, Ibn Tofail \\ University, Kenitra, Morocco. \\ 5- Laboratory Genetics and Biometrics, Faculty of Sciences, Ibn Tofail University, Morocco.
}

*Corresponding Author: youssefaz2007@gmail.com

\section{ARTICLE INFO}

Article History:

Received: April 3, 2020

Accepted: April 29, 2020

Online: May 2020

Keywords:

Parasitology,

Treatment,

Station,

Wastewater,

Helminth's eggs,

Azilal,

Morocco.

\section{INTRODUCTION \\ INTRODUCTION}

In the context of saving human health against waterborne diseases, the present work is interested in the study of some parasitological characteristics of raw and treated wastewater from the treatment station of Azilal city. The purpose of the analysis is to determine the parasite load, hence the abatement of the station, the samples analyzed were taken between August 2013 and May 2014, aimed to detect the presence of eggs of some parasites, the examination of the latter was based on the technique of Bailenger. Furthermore, for raw wastewater at the station entrance, the results revealed the presence of Helminth's eggs with a load of 39.3 eggs/1. The phylogenetic study isolated three different classes: Nematodes, Cestodes, and Strongles respectively with a load of 27.7, 7, and 4.6 eggs/l. However, the distribution of these collected eggs shows that the Nematode class is most represented with five species, followed by the Cestodes class with three species. For treated wastewater at the station exit, we isolated Helminth's eggs at an average concentration of 3.6 eggs/l of which 2.7 eggs/l correspond to Nematode, $0.5 \mathrm{eggs} / 1$ at Cestodes, and $0.4 \mathrm{eggs} / 1$ at Strongles. In light of these results, it can be said that the station does not ensure the total elimination of Helminth's eggs. These results remain far from those encountered in the literature.

The world currently suffers from environmental pollution, which is generally due to the increase in human activities in all sectors, and it causes damages to human health and 
to the ecological balance. For this reason, all countries have made efforts to solve this problem, specially of scarcity and the deterioration of water quality because of the diversity of sources of water pollution. To address this environmental pollution problem, developing countries have launched great projects in this direction. As a result, most of these countries have installed wastewater treatment stations. In Morocco, the natural water resources still available are limited and at the same time large quantities of wastewater from the main urban agglomerations are released into the natural environment without treatment. So widespread, massive, and more varied pollution poses a risk to the receiving environment, this situation has forced the consideration of wastewater as an integral part of Morocco's water heritage. Among these sources of pollution, the production of wastewater discharged into the natural environment without prior treatment generates many water diseases. Nevertheless, before 2011, the city of Azilal had a remarkable demographic development, allowing local authorities to undertake initiatives to rehabilitate the old network and expand it. Hence the need for a treatment station (Fig.2). In order to enhance the quality of the treated wastewater from the station, and after completing the physicochemical characterization and metal loading study of the raw discharges from the city of Azilal, the results obtained led us to determine that the nature of the raw wastewater is domestic (Azami et al., 2015). In order to evaluate the station's performance, this work involves the parasitological study of raw and purified wastewater.

\section{MATERIALS AND METHODS}

\section{Geographical location of the city of Azilal}

The town of Azilal is located at the top Atlas of Morocco chain, south of the town of Beni Mellal (Fig.1), in a mountainous region, its relief is characterized by medium to low slopes in the center of the city and which become stronger by going to the outskirts, located at an altitude of $1351 \mathrm{~m}$. The center of Azilal had 27711 inhabitants according to the 2014 census of population and habitat, with an annual growth rate of $4.4 \%$.

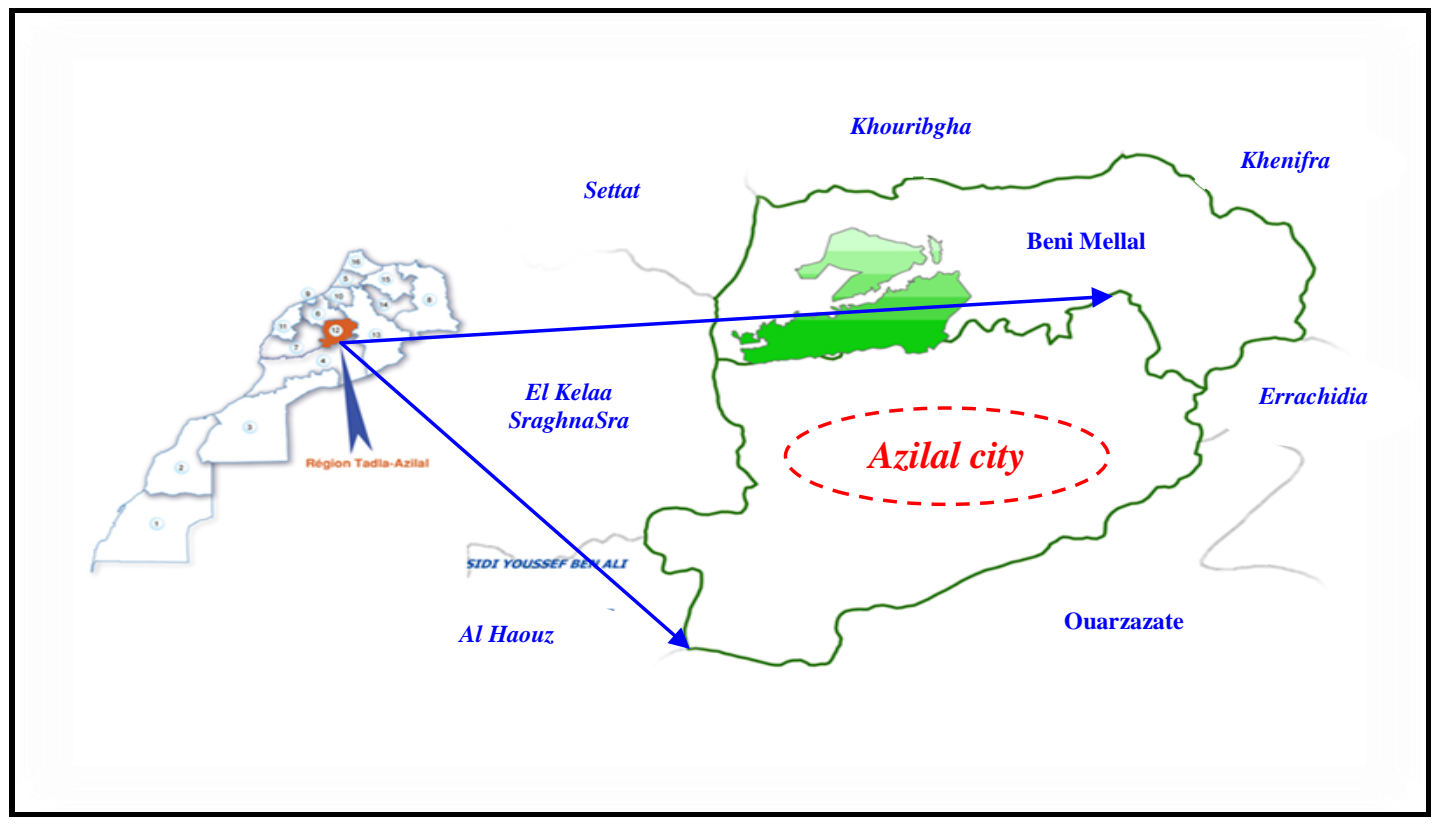

Fig.1: A map of the city of Azilal in Morocco. 


\section{Study area}

The wastewater treatment station in the city of Azilal (Fig.2) is intended for the collective sewage treatment of the city, located $2.5 \mathrm{~km}$ southeast of the city, these GPS coordinates are: Long $=-6.61823943^{\circ}$, Lat. $=31.93372120^{\circ}$, these average Lambert coordinates are: $\mathrm{X}=384666.216 \mathrm{~m}, \mathrm{Y}=149486.917 \mathrm{~m}$. It is sized to receive a nominal flow rate of $2611 \mathrm{~m}^{3} /$ day and to treat a pollutant load of $3460 \mathrm{~kg}$ of $\mathrm{BDO}_{5} /$ day (N.D.W.O., 2007). It has a total of 6 basins: 3 anaerobic basins, and 3 optional pools plus 1 grilleur, and 1 desablers. The size of these basins is identical and has a length of $205 \mathrm{~m}$, a width of $68 \mathrm{~m}$ and a depth of $1.2 \mathrm{~m}$ per basin with a useful volume of $15000 \mathrm{~m}^{3}$ each, and a length of stay between 17 and 29 days.

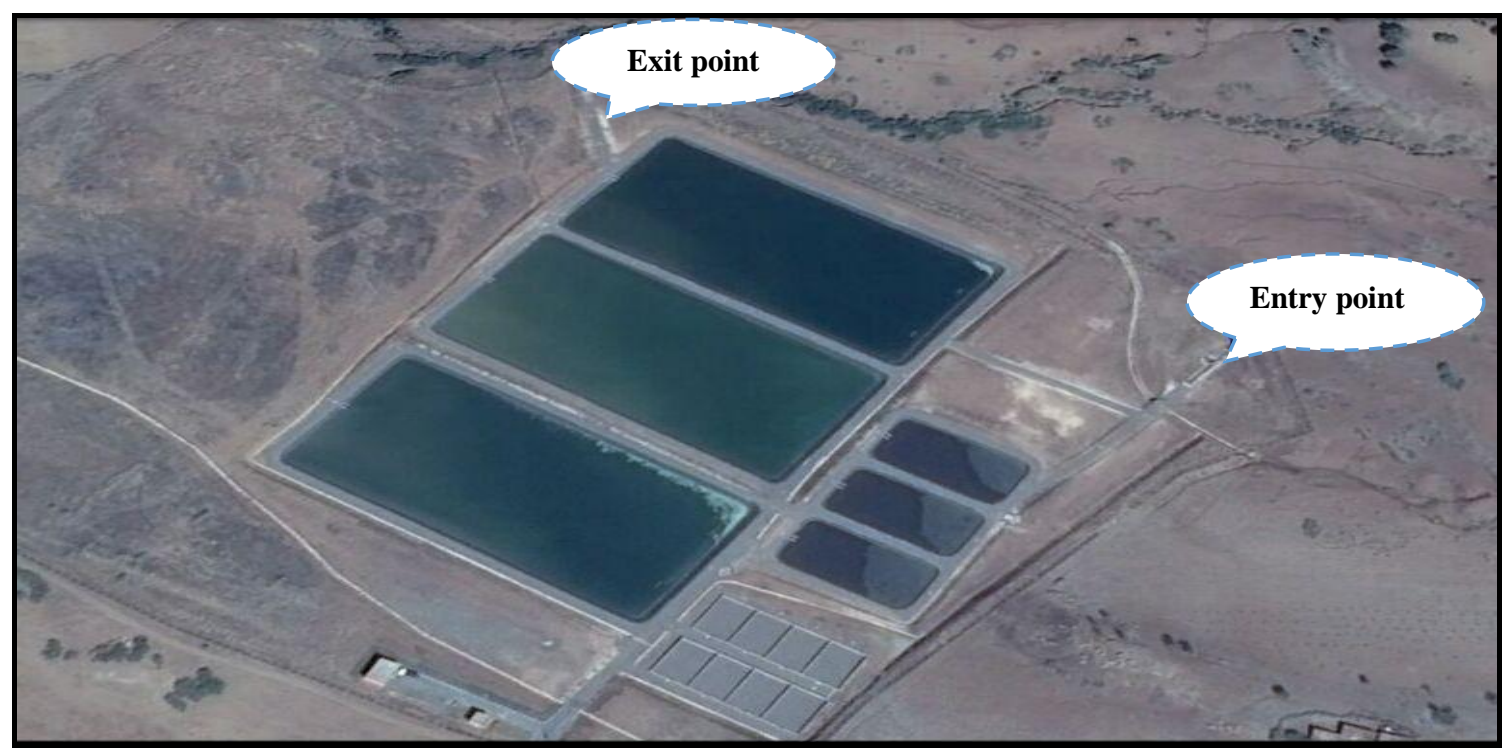

Fig.2: Projection of the Satellite Station of Azilal City. (Google earth)

\section{Period of sampling}

The samples were taken from August 2013 to May 2014. Sampling of raw and treated wastewater averaged two catches per month at the inlet and outlet. Samples of 2 liters of raw wastewater are collected using a bucket at the study site. They are transvased in polyethylene bottles and transported in a refrigerator with a temperature of about $4{ }^{\circ} \mathrm{C}$. For waste water samples for parasitological analysis are collected and stored by the addition of $10 \%$ formol ( $2 \mathrm{ml} /$ liter) in containers where they are left to decant in test tubes at least 2 hours according to the method proposed by WHO (1996).

\section{Methods of analysis parasitologic of waste waters}

In the laboratory, the samples of the wastewater are placed in the 1 liter test tubes, and then left decanted for 8 hours (one night), and the analyzes are retaken in the following day by a direct examination which consists of spreading a drop of the cap obtained after centrifugation between blade $(25.4 \times 76.2 \mathrm{~mm})$ and lamelle $(22 \times 22 \mathrm{~mm})$, followed by a microscopic observation under a binocular microscope with a camera. It should be noted that some parasitic elements (Ascaris sp. eggs, Strongles larvae, for example) are more easily found. For the identification of the different helminth eggs, we 
performed a concentration test using the modified Bailenger method (WHO, 1996). As this technique is followed by the identification and quantification of helminth eggs. In addition, the search and enumeration of the eggs of parasitic helminths is therefore limited to the species recognized by the WHO for their hygienic impact in humans and which can be identified by simple microscopic examination. The results of the parasitological study of wastewater are analyzed by statistical comparison of averages. The data entered is processed on a statistical software version 2016.

\section{RESULTS}

\section{Parasitological study: Qualitative and quantitative analyses}

In this section, we have been interested in studying some of the parasitological characteristics of the raw and treated wastewater of the treatment station, the study includes qualitative and quantitative analyzes to evaluate its purifying performance in terms of parasite load per season. The analysis is mainly devoted to the search for the eggs of certain parasites. In addition, the identification confirmed the presence of Helminth's eggs in the raw sewage of the city of Azilal, with an average load of 39.3 eggs/l.

Phylogenic study of these eggs isolated three different classes: Nematodes with an average initial concentration of 27.7 eggs/l, Cestodes with 7 eggs/l, and Strongles with 4.6 eggs/l. However, the distribution of these species by the nature of the species corresponding to the eggs collected shows that the Nematode class is most represented with five listed species such as Ascaris sp., Trichuris sp., Enterobius vermicularis, Ankylostome sp. and Nematodirus sp., followed by the Cestodes class with three species, Hymenolepis sp, Moniezia expansa and Taenia saginata. For treated wastewater, Helminth's eggs were isolated at an average concentration of 3.6 eggs/l, of which 2.7 eggs/l were Nematode eggs, 0.5 eggs/l at Cestodes and 0.4 eggs/l at Strongle.

The different mean concentrations of Helminth's eggs at the station entrance and exit are shown in (Fig.3).

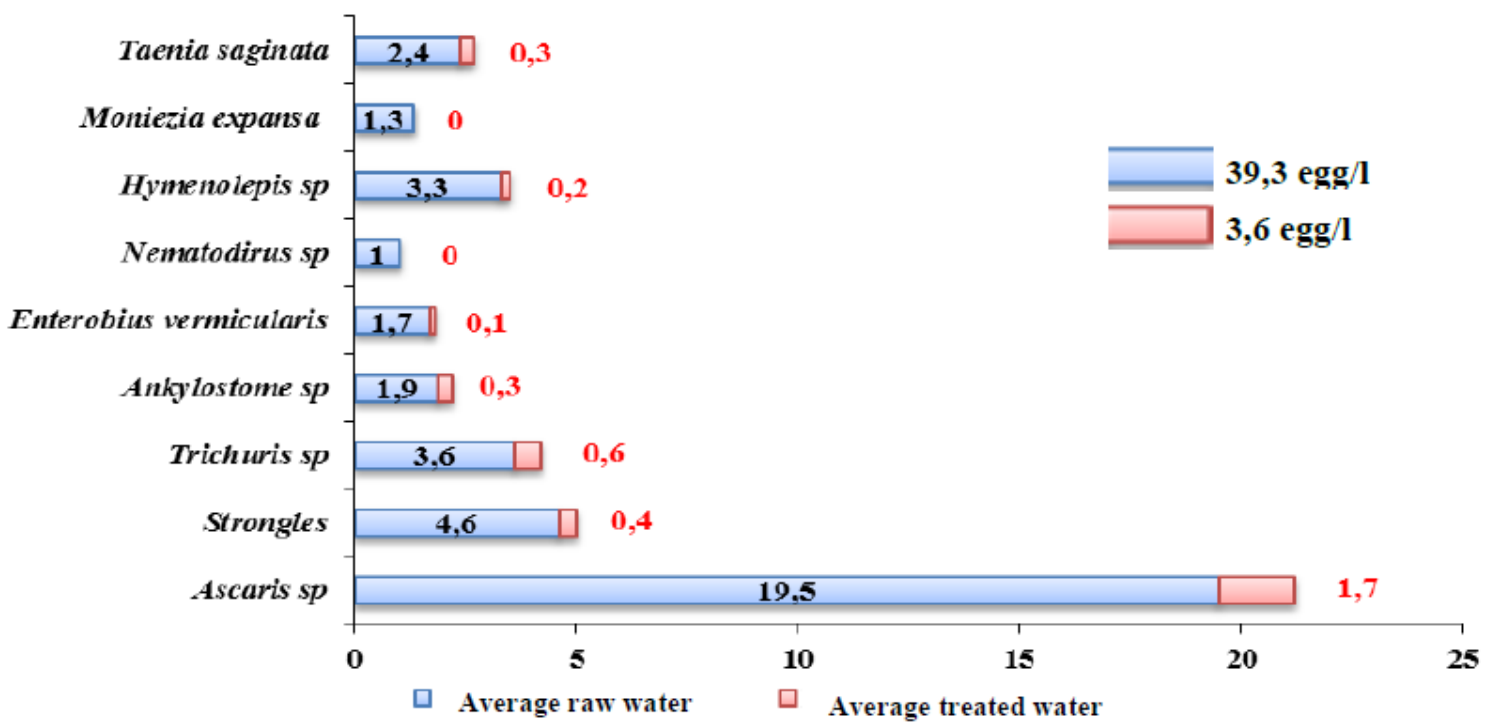

Fig.3: Average concentrations of helminth eggs in raw and treated wastewater. 
The quantitative analysis carried out during the sampling period is mainly related to the results of the average number of Helminth's eggs in raw and treated wastewater in the city of Azilal. The results are presented in (Fig.4).
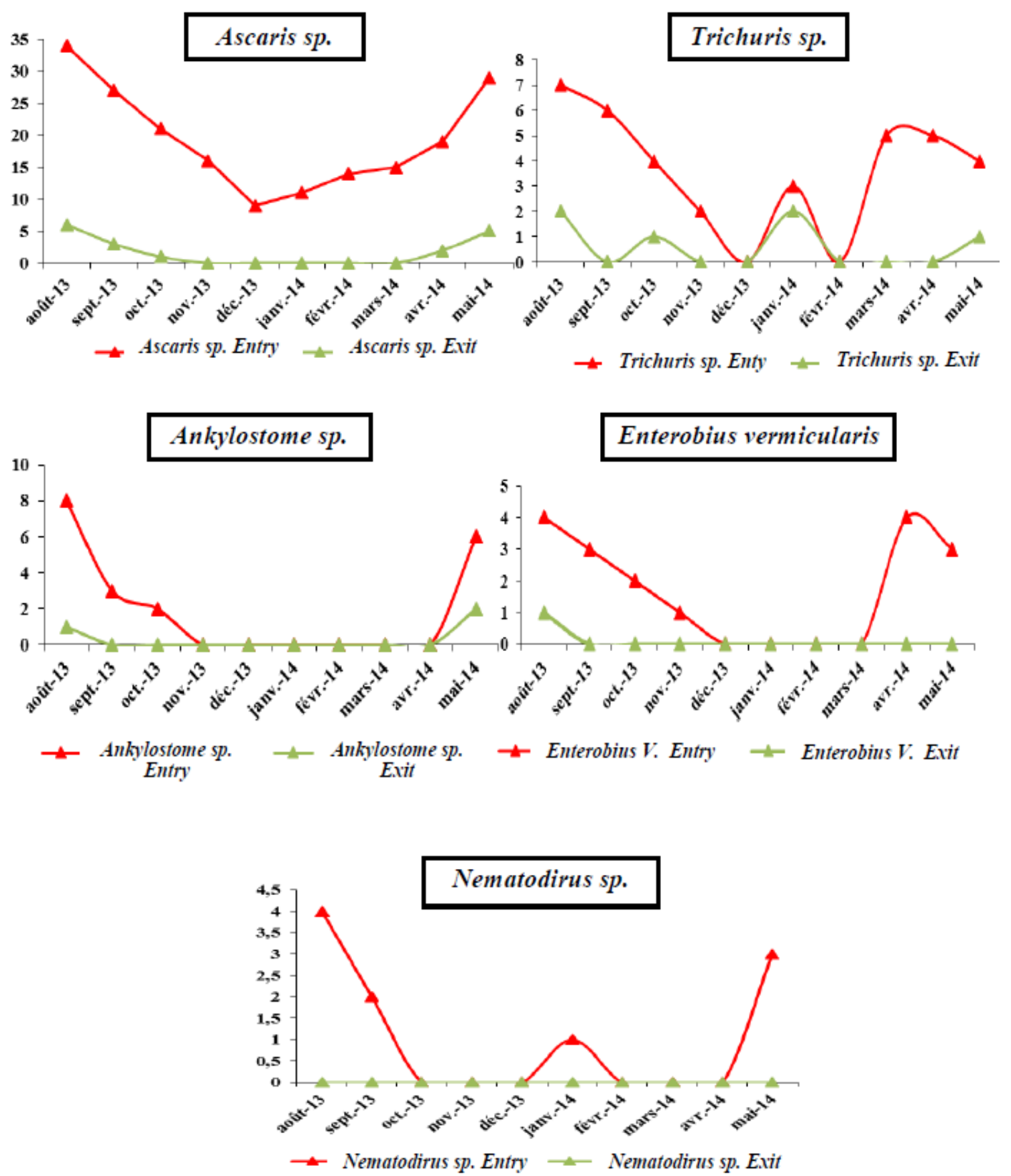

Fig.4: Monthly variation of Nematode eggs in raw and treated wastewater.

The distribution of Nematodes by densities expressed by number of eggs per liter of raw wastewater shows an abundance of Ascaris sp. eggs ( $\mathrm{n}=19.4 \mathrm{eggs})$, followed by 
Trichirus sp. eggs ( $\mathrm{n}=3.6$ eggs) and densities of no more than 2 eggs for Ankylostome sp., Enterobius vermicularis and Nematodirus sp. However, the number of pests in treated waters declined significantly from raw waters. The results show that the average density of Nematode worms is $1.7 \mathrm{eggs} / \mathrm{l}$ for Ascaris sp. and for the rest of the species (Trichirus sp. - Ankylostome sp. - Enterobius vermicularis) does not exceed 1 egg. By indicating that the abatement rate is more than $90 \%$.

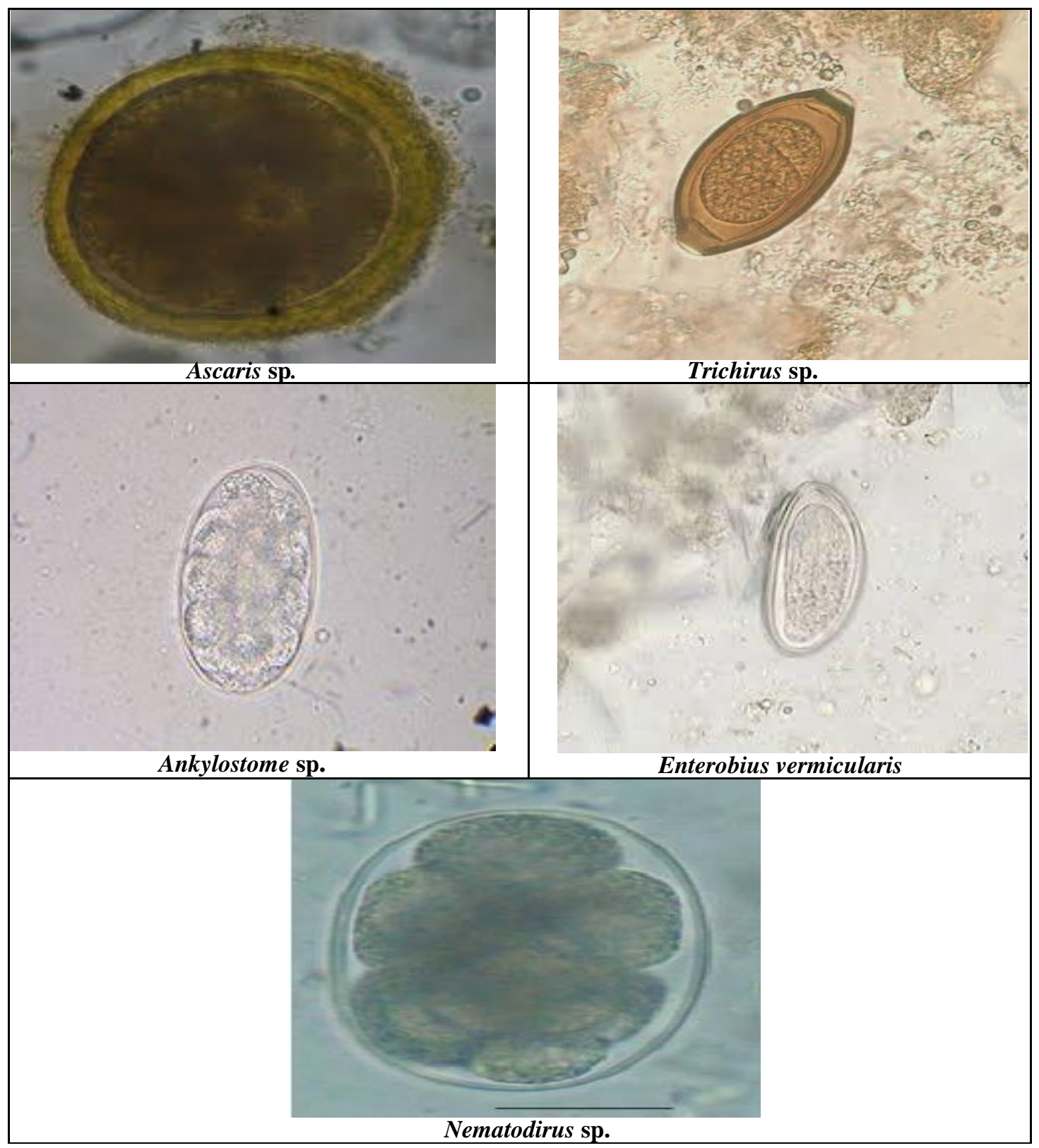

Fig.5 : Photos of eggs of the Nematodes species observed under the microscope 
Hymenolepis sp.

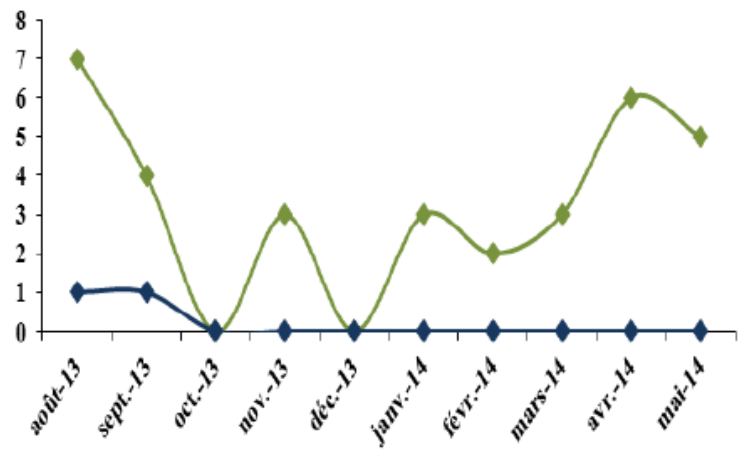

$\multimap$ Hymenolepis sp. $\rightarrow$ Hymenolepis sp. Entry
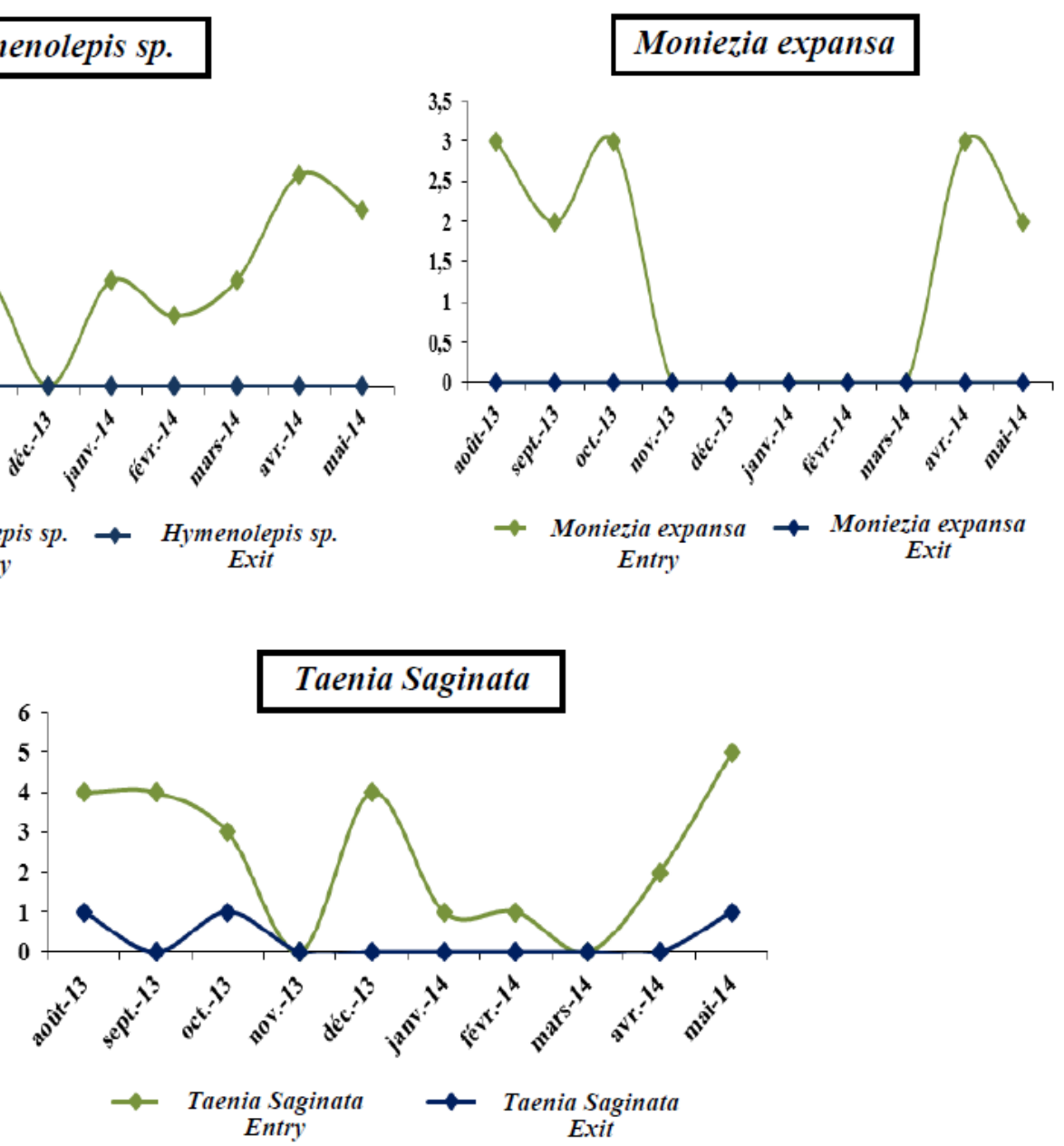

Fig.6: Monthly variation of Cestode eggs in raw and treated wastewater.

In raw waters, the average number of cestode eggs (Fig .6) identified is 3.3 eggs/1 for Hymenolepis sp., 1.3 eggs/1 for Moniezia expansa and 2.4 eggs/l for Taenia Saginata. These rates are lowered by $92.86 \%$ to 0.2 eggs/l in Hymenolepis sp., 0 eggs/l in Moniezia expansa and 0.3 eggs/l in Taenia Saginata.

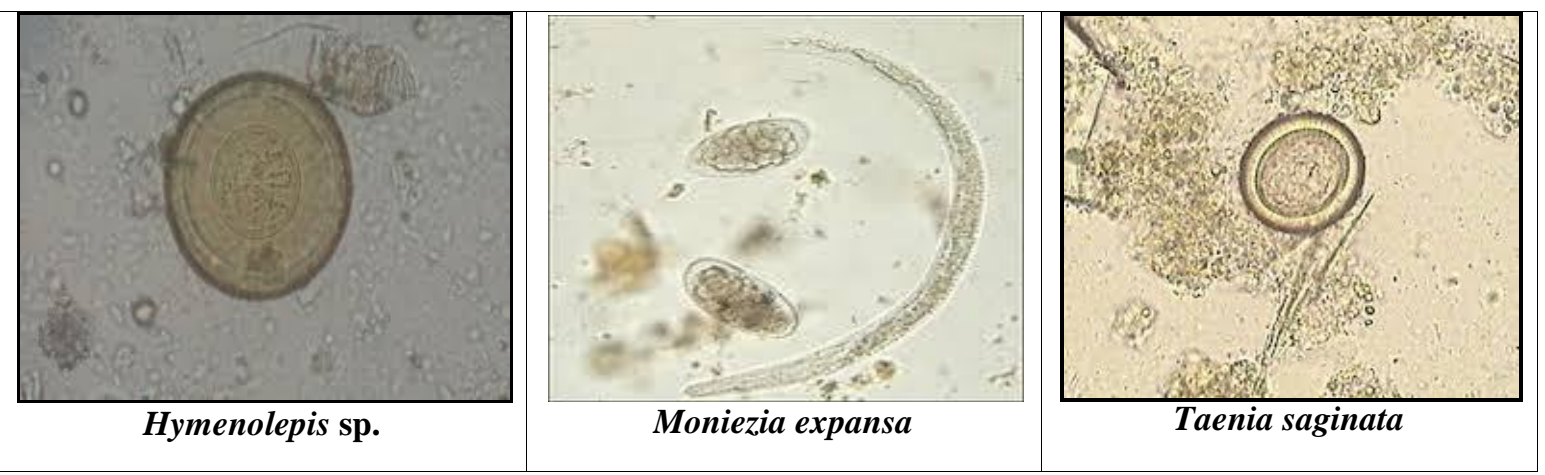

Fig.7: Photos of eggs of the Cestodes species observed under the microscope. 
Figure 7 depicts the photos of the different species and identifies eggs of the cestodes class taken by a photomicrograph.

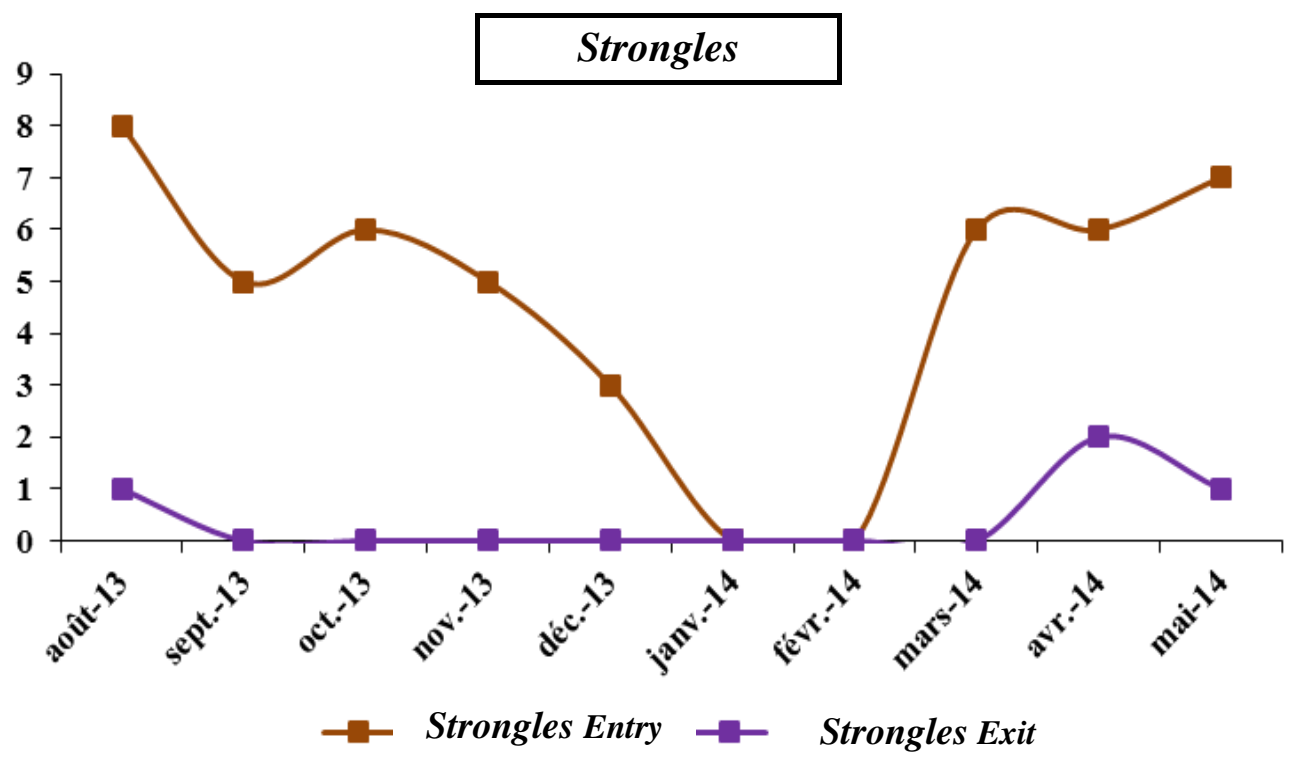

Fig.8: Monthly variation of Strongle eggs in raw and treated wastewater.

Strongles on their part represent a density of 4.6 eggs/l in raw waters, reaching 0.4 eggs/l after treatment, resulting in a abatement of $91.30 \%$. The results are presented in (Fig.8).

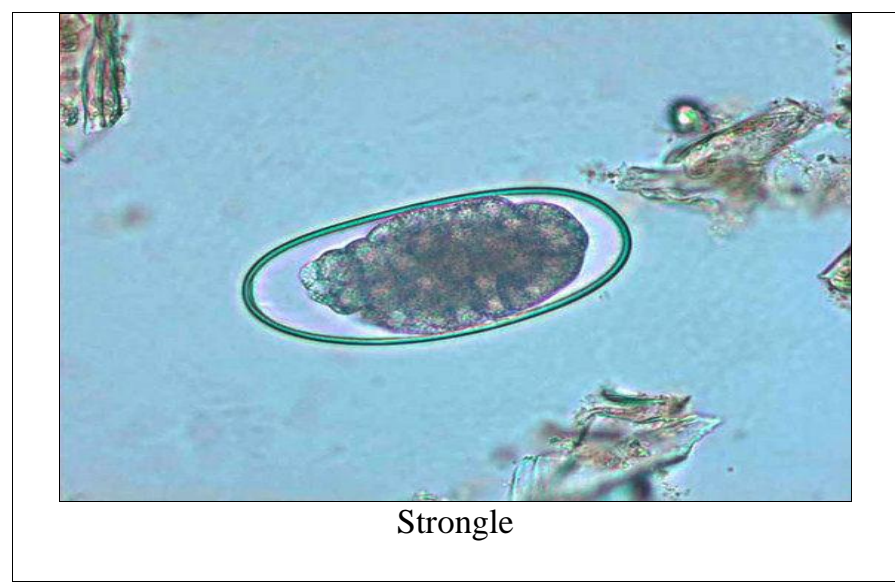

Fig.9: Photo of Strongle's egg under the microscope 


\section{DISCUSSION}

The parasitological study of raw wastewaters in the city of Azilal shows that the average densities of Helminth's eggs do not exceed 40 eggs/l. These values are slightly higher than those found in Beni Mellal with 25.3 eggs/l (Naour, 1996), Marrakech between 4 and 32 eggs/l (Mandi, 1993) and Ouarzazate with 18 eggs/l (Chalabi, 1993; Firadi, 1996), they approximate the densities encountered in Egypt which vary between 6 and 42 eggs/l (Shereif et al., 1995). Azilal's wastewater was highly charged in comparison with the wastewater of some European cities such as Nancy in France with 8 eggs/l (Stien and Schwartzbrod, 1987), and at a very low rate in comparison with the wastewater of some Latin American countries such as Brazil with 1490 eggs/l (Mara et Silva, 1986). Parasitic Helminth's eggs found in the raw sewage of Azilal belong to the classes of Nematodes, Cestodes and Strongles with a clear predominance of Nematodes. This biodiversity is probably related to the way of life of the working population whose culinary habits (meat consumption) do not promote the transmission of Cestodes (Mrabet, 1991), no Trematode eggs were identified during the study period. In addition, several authors reported that eggs in the intestinal Nematode class are more resistant to adverse wastewater conditions than Cestodes. The Helminth's eggs, which are isolated from raw and treated wastewater, are represented mainly by Ascaris sp., Strongles, Trichuris sp., Ankylostome sp., Enterobius vermicularis, Nematodirus sp., Hymenolepis sp., Moniezia sp., and Tania Saginata, with significant predominance of Ascaris' eggs. This diversity in the parasite spectrum identified in raw waters is attributed on the one hand to the different contamination of human and animal origin (Stott et al., 1997), and on the other hand to the qualitative and quantitative seasonal variations of Helminth's eggs. This evolution resulted in high Helminth eggs' levels, mainly for Nematodes and Cestodes, during the spring-summer period (hot period) and low levels during the fallwinter period (cold period). There were also lower levels for Strongle's eggs during the spring-summer period and low levels during the fall-winter period. In addition, several authors linked this difference in concentration between these two periods by increasing the parasitic prevalence of verminosis in Spring (Ait Abdelalai, 1983). While the WHO in 1989 reported that this abundance of Helminth's eggs in the spring-summer period is due to conditions of temperature, humidity, oxygen and solar radiation favorable to the maturation of these parasite Helminths in the outdoor environment. During the autumnwinter period, however, the climatic conditions are unfavorable for egg maturation and for dilution of Helminth's eggs by precipitation. At the station exit, the parasitological study revealed a very low percentage of some Helminth's eggs with an average concentration of $3.6 \mathrm{eggs} / \mathrm{l}$ and a percentage of abatement of $90 \%, 92 \%$ and $91 \%$, respectively, for Nematodes, Cestodes and Strongles with always high concentrations in hot periods, weak in cold period. In light of these results, it can be said that the wastewater treatment station in the city of Azilal does not ensure a total elimination of Helminth's eggs. These results are still far from those encountered in the literature by 
El Halouani in 1995, which demonstrate a total elimination of Helminth's eggs by the corresponding treatment station. Nevertheless, the eggs of helminths, characterized by a high density, are usually eliminated at the level of the first basin by simple settling. However, our results show that Helminth eggs' levels are low at the site, and this may be due to factors such as:

- The depth of the basins which not exceed 1,2 $\mathrm{m}$ and the absence of the basins of maturation.

- The length of stay that may be insufficient in optimal conditions for egg sedimentation.

- Handing-over in suspension of eggs by the carbonization gases following fermentation.

- Non-uniformity of flow and significant presence of detergents in raw wastewater.

Finally, following the parasitological results found in the treated wastewater of Azilal, it is impossible to reuse the treated water either in agriculture irrigation or in daily use. WHO (1996) recommended its use to a total absence of these eggs/l. This work shows that the Helminth eggs' load of treated wastewater presents a clear potential risk to the human population and to the livestock. As a result, this type of treatment requires adequate control in the case of reuse in agriculture.

\section{CONCLUSION}

This study described the purifying performance levels of the wastewater treatment plant in the city of Azilal. The results obtained for the purifying yields of this unit are not encouraging. As a result, it does not achieve a total elimination of parasitic elements in accordance with the standards for sewage discharge recommended by Moroccan and European structures. For the parasitological descriptive study, it can be said that the analysis of seasonal variations showed that the highest concentrations were recorded during the spring-summer season, only $91 \%$ of eggs were removed at the site. The final effluent from the Azilal natural lagoon does not meet WHO guidelines for reuse in agriculture. These values show a poor purifying performance of the plant in terms of parasitology, due to the size of the ponds, the quality of the effluent produced makes them unsuitable for re-use for irrigation of agricultural land, which requires very thoroughly work for the rehabilitation of the station and its resizing for better operation.

\section{REFERENCES}

Ait Abdelalai, R. (1983). Intestinal parasitoses in the province of Marrakech from 1978 to 1982, Thèse Médecine. Fac. Med. Phar. Casablanca.

Azami I. Y.; Alemad A.; Aboubaker, S; Daifi, H.; Elkharrim, K. and Belghyti, D. (2015). Physicochemical characterization of wastewater from The city of AzilalMorocco, International Journal of Innovation and Applied Studies, 11( 3): 556-566. 
Chalabi, M. (1993). Helminth eggs elimination performance and study of their viability in the High Yield Algal Channel, 3rd cycle thesis. Fac. Sci. Marrakech, 120pp.

EL Halouani, H. (1995). Reuse of wastewater in agriculture and its impact on the environment: Case of the city of Oujda, Doctoral thesis in Sciences, Fac. Sci., Univ. Mohammed Premier, Oujda, 193pp.

Firadi, R. (1996). Purification and reuse of wastewater from the city of Ouarzazate in agriculture: Becoming eggs of helminths and study of their viability in wastewater and sludge. 3rd cycle thesis, Fac. Sci., Marrakech, 126pp.

Khnifi, A. (1987). Intestinal parasites in the Oujda hospital center from 1978 to 1986, Thèse de Médecine. Fac. Med. Phar. Casablanca, 175pp.

Mandi, L.; Darley, J.; Barbe J. and Baleux, B. (1993). Essays for purifying wastewater from Marrakech using water hyacinth (organic, bacterial and parasitological load). Water Science Journal, pp. 313-333.

Mara, D. D. and Silva S. A. (1986). "Removal of intestinalis nematode eggs in tropical waste stabilization ponds" J. Trop. Med. Hyg. 89: 71-74.

Mrabet, K. (1991). Study of the contamination of spreading fields in the city of Oujda by helminth eggs and their transmission in the food web, Th. 3rd cycle. Fac. Sci. Oujda, 120pp.

Naour, N. (1996). Impact of reuse of waste water in agriculture on the contamination of crops by helminths. Thesis of the 3rd cycle, Cady Ayad Marrakech University, $120 \mathrm{pp}$.

National D. W. O., (2007). Environmental assessment of the sanitation project in the town of Azilal, Morocco.

Shereif, M.; EL Eassa, M.; El Samra, M. I. and Mancy, K. H. (1995). A demonstration of wastewater treatment for reuse applications in fish production and irrigation in Suez. Egypt. Wat. Sc. Tech. 32(11): 137-144.

Stien J. L. and Schwartzbrod, J. (1987). Becoming helminth eggs during an urban wastewater treatment cycle, International review of water series, 3 (3/4): 77-82.

Stott, R.; Jenkins, T.; Shabana, M. and May, E. (1997). A survey of the microbial quality of wastewater in Ismailia, Egypt and the implications for wastewater reuse. Wat. Sc. Tech., 35 (11-12): 211-217.

WHO. (1989). Use of wastewater in agriculture and aquaculture: health-related recommendations, Technical Report series, Geneva, 778: 84pp.

WHO. (1996). Analysis of wastewater for recycling in agriculture. Manual of laboratory techniques in parasitology and bacteriology, Geneva, 31pp. 